\title{
Conversion Disorder in a Depressed Patient: The Analysis of Paralysis
}

\author{
Michael A. Chen Ph.D. \\ University of Michigan Medical School, Ann Arbor, MI \\ David S. Im M.D. \\ Department of Psychiatry, University of Michigan Medical Center, Ann Arbor, MI
}

Follow this and additional works at: https://jdc.jefferson.edu/jeffjpsychiatry

Part of the Psychiatry Commons

Let us know how access to this document benefits you

\section{Recommended Citation}

Chen, Michael A. Ph.D. and Im, David S. M.D. (2001) "Conversion Disorder in a Depressed Patient: The Analysis of Paralysis," Jefferson Journal of Psychiatry. Vol. 16 : Iss. 1 , Article 3.

DOI: https://doi.org/10.29046/JJP.016.1.002

Available at: https://jdc.jefferson.edu/jeffjpsychiatry/vol16/iss1/3

This Article is brought to you for free and open access by the Jefferson Digital Commons. The Jefferson Digital Commons is a service of Thomas Jefferson University's Center for Teaching and Learning (CTL). The Commons is a showcase for Jefferson books and journals, peer-reviewed scholarly publications, unique historical collections from the University archives, and teaching tools. The Jefferson Digital Commons allows researchers and interested readers anywhere in the world to learn about and keep up to date with Jefferson scholarship. This article has been accepted for inclusion in Jefferson Journal of Psychiatry by an authorized administrator of the Jefferson Digital Commons. For more information, please contact: JeffersonDigitalCommons@jefferson.edu. 


\title{
Conversion Disorder in a Depressed Patient: The Analysis of Paralysis
}

\author{
Michael A. Chen, Ph.D. ${ }^{1}$ and David S. Im, M.D. ${ }^{2}$
}

\begin{abstract}
Patients presenting with neurologic and pseudoneurologic symptoms present both a diagnostic and treatment challenge. This case report describes the ER course of a man who presented with aphonia and paralysis, his medical clearance, transfer to the psychiatric ER and subsequent recovery. The history of conversion disorder and its characteristics are briefly reviewed, and the etiology of this patient's symptoms and a discussion of effective treatment plans are discussed.

Although the concept of conversion symptoms dates at least to the ancient Greeks and was discussed by Freud and Breuer in Studies on Hysteria (1) in the late 1890 's, it has been an increasingly infrequent (although not rare) diagnosis. In contrast to most other DSM diagnoses, unconscious processes or conflicts are implicated in the development of conversion disorder. Conversion disorder generally involves a symbolic relationship between an underlying psychological conflict and disturbed physical functioning. "Classic" symptoms include paralysis, aphonia, seizures, malcoordination, dyskinesia, blindness, anesthesia, and parasthesias. The disorder has been most commonly described in rural women of lower socio-economic status. The following case describes a well-educated man who was brought to the Emergency Department after becoming acutely unresponsive (with paralysis and aphonia), and highlights his subsequent course in the emergency setting.
\end{abstract}

\section{CASE REPORT}

Mr. B was a 47-year-old man who was brought to the Medical ER unresponsive to verbal commands (but responsive to ammonia), with paralysis and aphonia. According to one of Mr. B's coworkers, earlier that day Mr. B had been fired from his job, and following an argument with his boss, Mr. B became verbally noncommunicative and began to hyperventilate. Shortly thereafter he collapsed, and an ambulance was called. Upon arrival to the Medical ER he remained unresponsive, though on rare occasions his eyes would open to voice. During these times he would intermittently become tearful when asked about the earlier events of that day.

\footnotetext{
${ }^{1}$ Fourth Year Medical Student, University of Michigan Medical School, Ann Arbor, MI 48109

${ }^{2}$ Psychiatric Resident, Department of Psychiatry, University of Michigan Medical Center, Ann Arbor, MI 48109
} 
Physical examination (including a detailed neurologic exam) was reportedly unremarkable. Because staff could not rule out toxic ingestion, a nasogastric lavage was performed with activated charcoal administration. Oxygen saturation by pulse oximetry was 98\%, and blood and urine toxicology screens were negative. An electrocardiogram was normal. After three hours in the Medical ER, it was felt by the ER staff that no clear medical or neurological etiology could account for Mr. B's clinical presentation, and an urgent psychiatric referral was made.

Upon arrival to the Psychiatric Emergency Room Mr. B was somewhat able to move his arms, but unable to sit up or speak. Over the next few hours he displayed a slow, gradual improvement in his mobility and ability to vocalize, initially voicing (with great difficulty) one-word phrases such as "wife" and "daughter," and later indicating that he did not want any of his family to be contacted. After this significant change in his status, a full neurologic examination was performed. This was entirely within normal limits (in particular, there was no evidence of any sensory/motor deficits, abnormal muscle tone, abnormal reflex responses, or other focal abnormalities). Mental status examination was notable only for mildly impaired attention/ concentration (slow serial sevens) and short-term memory (he remembered the third of three objects on delayed recall only after being prompted with the first letter).

Once he was finally able to vocalize, Mr. B provided information regarding his past psychiatric history. He reported seeing a psychologist for a short time in high school for "depression," stating that this was not particularly helpful. Four years prior to this episode, while on a business trip, he became angry and "tore up a hotel room" (e.g., throwing furniture and other objects). At that time he was admitted to a psychiatric hospital overnight, and was released on Xanax and an antidepressant (he could not remember the name). At the time of our evaluation, Mr. B's wife was living at her mother's house. Mr. B eventually gave permission for staff to call his wife. Discussion with his wife confirmed that she was staying with her mother, but that she (according to his wife) was doing so because of Mr. B's violent behavior (smashing and throwing household objects) and verbal abuse. Three months prior to our evaluation, Mr. B reported calling 911 "on himself" after he had threatened to throw his wife down the stairs. Mr. B also reported a vague history of suicidal ideation in the past (no attempts), and minimized the significance of these thoughts. He cited his relationship with his biological daughter as one reason he would not commit suicide. However, he also admitted to recently telling his wife that she "might as well keep the insurance because I'd be better off dead." He denied any homicidal ideation.

Mr. B reported no significant past medical history, nor was he taking any medications at the time of our evaluation.

The patient's family history was significant for alcohol abuse in both parents. He reported that his mother died from complications of alcoholic cirrhosis, and that his father had struggled with depression as well as alcoholism. He reported no history of physical or sexual abuse as a child.

Mr. B was a college graduate, and had obtained a Master's degree in physics as well as a partial computer science degree. He had worked in the field of computer 
science for twenty years. At the time of his presentation, he was involved in the sale of computer software. He had been working 60 hours a week, and was aware of declining work performance over the last six months.

The patient reported living at home with his wife, her daughters from a previous marriage, and his daughter. He emphasized that he had a particularly good relationship with his biological daughter, and that he was getting along well with his former wife (who had also remarried) and her husband.

Mr. B reported that for the past two years he had experienced worsening depressive symptoms, including decreased sleep, impaired concentration, low energy, diminished appetite, and feelings of hopelessness and worthlessness. These symptoms had occurred in the context of a number of psychosocial stressors. First, as noted previously, Mr. B had been experiencing severe work stress and had noted a recent decline in his work performance culminating in his termination on the day of our evaluation. Second, Mr. B reported that he and his wife were involved in a custody battle over his wife's children from a previous marriage. They could not afford to pay both the legal fees and their taxes, and they elected to pay the lawyers. As a result, the IRS claimed a lien on his wages. Third, Mr. B's wife had been unable to work secondary to an accident she sustained while being treated by a chiropractor; this caused her to become "essentially paraplegic." Finally, his wife had recently threatened him with divorce.

Because of Mr. B's questionable suicidal ideation, his worsening depressive symptoms, and his limited insight into his long-standing emotional and other problems as well as his lack of clear plans for dealing with these stressors, he was involuntarily admitted to an outside psychiatric facility for further evaluation and treatment (He could not be admitted to our facility due to a lack of legal reciprocity regarding involuntary commitment between Mr. B's home county and our facility's). At the outside hospital, he was observed overnight and received only supportive treatment from staff. He continued to display no reemergence of conversion symptoms, and was discharged the following day.

\section{CASE DISCUSSION}

The modern belief that psychological factors are involved in conversion disorder comes from work done by Amroise-Auguste Liébaut and Hippolyte Bernheim in the late nineteenth century at the Nancy School in Paris. In research conducted there, symptoms such as blindness, numbness, deafness and paralysis were produced in and removed from healthy individuals via hypnotic suggestion (2). The neurologist Charcot made important contributions to the study of this disorder as well. Although at one time he argued that hysterical disorders resulted from the degeneration of parts of the brain, he ultimately embraced the idea that psychological factors were critical in the development of hysterical symptoms (3). An important contribution he made was his development of a neurologic examination which could provide objective analysis of symptomatology (4). Janet, one of Charcot's students, deemphasized the psychological etiology of hysterical symptoms, instead focusing more on physical 
states that could be predisposing, such as typhoid fever, hemorrhage, and intoxication. Interestingly, he also outlined the personality characteristics often found in "hysterics," such as a sexual preoccupation and egocentricity (5). In the late 1890s Freud, another of Charcot's students, wrote (with Breuer) Studies on Hysteria, in which they outlined a psychodynamic understanding of conversion; that the symptoms represent the conversion of underlying emotional conflicts into physical symptoms (6). It was during his studies of patients with hysteria that Freud developed psychoanalysis. Other more contemporary explanations of the disorder include the cognitive view and the behavioral view. The cognitive view contends that conversion symptoms represent a form of communication (as opposed to a defense) whereby emotions patients could not otherwise express are expressed. Furthermore, proponents of this view emphasize that the actual symptom is often one that has been observed in others, or has been experienced by the patient in the past as a result of a genuine physical malady (7). According to the behavioral view, conversion symptoms enable the patient to receive rewards such as attention from others (8).

A more integrative understanding is expressed by Stoudemire, who writes that "conversion symptoms result from stressful environmental events acting on the affective part of the brain in predisposed individuals" (9). This phenomenon can be conceptualized as the conversion of a repressed idea or psychological conflict into a somatic symptom. As such, conversion symptoms may be a means to express forbidden feelings and/or ideas or they may be an acceptable means of enacting the sick role, or both.

The definition of conversion disorder has changed over the years. It was called "conversion reaction" in the Diagnostic and Statistical Manual of Mental Disorders-I (10) and "hysterical neurosis-conversion type" in DSM-II (11). In both, it was restricted to symptoms affecting the voluntary motor and sensory nervous systems. In DSM-III (12) and DSM-IIIR (13), the definition was broadened to include symptoms involving any "loss or alteration in physical functioning suggesting a physical disorder," if the symptoms could be seen as "an expression of a psychological conflict or need." In $D S M-I V$, the definition was narrowed to once again encompass symptoms affecting the voluntary sensory and motor nervous systems (14).

Mr. B met the DSM-IV criteria for conversion disorder (15). He experienced a loss of or alteration in physical functioning suggesting a physical/neurological disorder, in this case paralysis and aphonia. A physiological basis for these symptoms, however, was not detected. Psychological factors (extreme stress) were judged to be etiologically related to the physical symptoms, as the onset of these symptoms coincided with his being fired from work. He did not seem to be conscious of or intentionally producing the symptom. For example, he allowed gastric lavage in the ER, an intensely unpleasant procedure. His apparent paralysis was not a culturally sanctioned response pattern and could not be explained by a known physical disorder. His symptoms caused clinically significant distress and impairment in social, occupational, or other important areas of functioning and warranted medical attention. It also was not limited to pain or sexual dysfunction, and did not occur 
exclusively during the course of somatization disorder, and was not better accounted for by another medical disorder.

Mr. B's history of depression supports his recent development of conversion symptoms, as the latter symptoms often occur as part of mood disorders. In a prospective study of conversion "catatonia," Abrams and Taylor found that of 55 patients studied over 14 months, two-thirds of patients with catatonia had diagnosable affective disorder (16). Mersky noted that conversion symptoms more often appear as part of a depressive illness than as a precursor of schizophrenia (17). The disorder may also present as a part of somatization disorder, schizophrenia, organic brain syndromes, medical or neurological disease.

Conversion disorder is relatively common (although less so than its predecessor, hysteria, was at the turn of the century). It has a $5-14 \%$ prevalence in general medical admits (18). Onset of symptoms is most common between 10 and 35 years of age. It tends to occur in people with lower socio-economic status, less education, less psychological sophistication and/or in people who live in rural areas $(19,20)$. It is also reported to be more often found in women than men at ratios ranging from 2:1 to $10: 1(21)$.

The course of conversion disorder is usually short, but $20-25 \%$ will relapse within a year (22). A good prognosis is suggested by acute onset, a clearly identifiable stressor at time of onset, a short interval between onset of symptoms and treatment, and intelligence. Other good prognostic factors include conversion symptoms of blindness, aphonia, and paralysis, whereas seizures and tremor indicate a poorer prognosis (23). One study found that by far the strongest predictor of a good outcome at follow up (median 4.5 years) was marked improvement before discharge following the initial hospitalization (24). It is also important to acknowledge that a number of follow-up studies (as long as 10 years) of patients diagnosed with conversion have reported an incidence of subsequent organic (most often neurological) disease that explained the initial symptoms as high as $34 \%(25,26,27,28)$.

The differential diagnosis for conversion includes physical disorders (e.g. neurologic dysfunction), somatization, schizophrenia, sexual dysfunction, somatoform pain disorder, hypochondriasis, factitious disorder, and malingering.

Although a detailed psychodynamic assessment of a person seen once in an ER setting is difficult, some reasonable inferences can be made in this case. By his wife's report (and by his own admission), Mr. B appeared to have problems dealing with anger. It is reasonable to suggest that Mr. B's long-standing aggressive impulses emerged in a field of strong inhibition of their expression (e.g., professional environment of the workplace), resulting in a conflict that overwhelmed his ordinary ego defense mechanisms. In this setting, unconscious mechanisms worked to develop a compromise that allowed a partial expression of the primitive impulse but disguised it so that Mr. B was unaware of the unconscious and unacceptable wish (to kill his wife who had been threatening to leave him, to kill his boss who had fired him). In addition, the formation of his conversion symptoms may have embodied a symbolic aspect of the intrapsychic conflict; it is of interest that one of Mr. B's presenting symptoms was paralysis, given his wife's history of sustaining a back injury that 
rendered her unable to move her arms or legs. The observation of neurologic symptoms by $\mathrm{Mr}$. B is an etiologic feature consistent with the cognitive view of conversion.

It is also interesting to speculate more specifically about how Mr. B's depression might be related to his conversion symptoms. Jensen described a depressed soldier with bipolar affective disorder who became acutely catatonic after an argument with a staff member on a psychiatric ward (29). He became mute, unresponsive and exhibited waxy flexibility. He was "cured" with hypnosis over the course of 80 minutes. His physician saw the patient's symptoms as being a response to environmental stress and anger. Psychodynamic theorists have conceptualized depression as unconscious rage at the loss of an ambivalently loved object, that has been turned inward. In that sense, then, Mr. B's unconscious rage may have manifested itself in both depression and more acutely in the conversion symptoms. Although we have little information about Mr. B's early relationships with others (objects), we might speculate that his relationship with one or both parents was problematic due to their alcoholism. For example, his mother's death from bleeding esophageal varicies might have occurred early in his life or she might have been absent from him either physically or emotionally. Similarly, his relationship with his father, which he now reports as good, might have been strained early on in his life.

Discussions of conversion disorder usually emphasize its simple treatment in the acute setting, as it has been shown to respond to virtually any therapeutic intervention (e.g. a farmer, blinded after seeing a mortgage foreclosure notice, was "cured" by saline drops (30)). Indeed, Mr. B's paralysis and aphonia resolved spontaneously over the course of a few hours as psychiatric ER staff spoke to him. However, while the acute management of conversion reactions may appear simple, important steps that should be taken to prevent future episodes are often underemphasized. In this case, dealing with the underlying conflict is likely to be effective in preventing future conversion episodes. Prompt recovery is much more common than a chronic course, which has a much worse prognosis. Although many factors point to a good prognosis for Mr. B (symptoms of aphonia and paralysis, acute onset, clear preceeding life stressor, intelligence, rapid improvement before discharge), his underlying conflicts undoubtedly remained, and from a psychodynamic perspective, without adequate resolution of the underlying conflict, relapse, symptom substitution or more violent outbursts could occur in the future. Follow-up will be vital, and it is of critical importance that it address the patient's mood disturbance-if not acutely, at least in an outpatient setting. Given previous studies showing an increased incidence of organic disease among patients diagnosed with conversion, it must also include adequate medical follow-up.

This case illustrates that conversion disorder should be in the physician's differential for the acute onset of disturbances in physical functioning such as paralysis, anesthesia, seizures, blindness, and catatonia. Furthermore, it shows that although conversion symptoms are reported to occur more commonly in women, people of lower socioeconomic status, less educated individuals, and rural residents, the disorder can occur in male, middle-income, well-educated city-dwellers (31). 
Finally it should be noted that adequate recognition of conversion symptoms has important implications not only in terms of simplicity of acute management, but also in terms of enhancing the efficacy of what should be considered essential preventative medicine, if appropriate follow-up plans and referrals are made.

\section{REFERENCES}

1. Breuer J: Studies in Hysteria. New York: Nervous and Mental Disease Publishing Company, 1936.

2. Comer RJ: Abnormal Psychology. New York: W.H. Freeman and Company, 1992.

3. Comer RJ: Abnormal Psychology. New York: W.H. Freeman and Company, 1992.

4. Merksky H: The Analysis of Hysteria. London: Bailliere Tindall, 1979.

5. Merksky H: The Analysis of Hysteria. London: Bailliere Tindall, 1979.

6. Breuer J: Studies in Hysteria. New York: Nervous and Mental Disease Publishing Company, 1936.

7. Ziegler FJ, Imboden JB: Contemporary conversion reactions. II. A conceptual model. Arch Gen Psychiat 1962; 6: 279-287.

8. Comer RJ: Abnormal Psychology. New York: W.H. Freeman and Company, 1992.

9. Stoudemire A: Clinical Psychiatry for the Medical Student. Philadelphia: J.B. Lippincott, 1994.

10. American Psychiatric Association: Diagnostic and Statistical Manual of Mental Disorders, first edition. Washington, DC: American Psychiatric Association, 1952.

11. American Psychiatric Association: Diagnostic and Statistical Manual of Mental Disorders, second edition. Washington, DC: American Psychiatric Association, 1968.

12. American Psychiatric Association: Diagnostic and Statistical Manual of Mental Disorders, third edition. Washington, DC: American Psychiatric Association, 1980.

13. American Psychiatric Association: Diagnostic and Statistical Manual of Mental Disorders, third edition, revised. Washington, DC: American Psychiatric Association, 1987.

14. American Psychiatric Association: Diagnostic and Statistical Manual of Mental Disorders, fourth edition. Washington, DC: American Psychiatric Association, 1994.

15. American Psychiatric Association: Diagnostic and Statistical Manual of Mental Disorders, fourth edition. Washington, DC: American Psychiatric Association, 1994.

16. Abrams R, Taylor MA: Catatonia: a prospective clinical study. Arch Gen Psychiatry 1976; 33: 579-581.

17. Merskey H. Conversion disorders, in Treatment of Psychiatric Disorders: A Task Force Report of the American Psychiatric Association, Vol. 3. Washington, D.C.: American Psychiatric Association, 1989: 2152-2159.

18. Folks DG, Ford CV, Regan WM: Conversion symptoms in a general hospital. Psychosomatics 1984; 25: 285-289.

19. Folks DG, Ford CV, Regan WM: Conversion symptoms in a general hospital. Psychosomatics 1984; 25: 285-289.

20. Lazare A: Conversion symptoms. N Engl J Med 1981; 305: 745-748.

21. Martin RL, Yutzy SH: Somatoform disorders, in Psychiatry. Edited by Tasman A, Kay J, Lieberman JA. Philadelphia: W.B. Saunders Co., 1997: 591-622.

22. Hales RE, Yudofsky SC, Talbot JA: The American Psychiatric Press Textbook of Psychiatry, second edition. Washington, DC: American Psychiatric Press, 1994. 
23. Toone BK: Disorders of hysterical conversion, in Physical Symptoms and Psychological Illness. Edited by Bass C. London: Blackwell Scientific Publications, 1990; 207-234.

24. Couprie W, Wijdicks EFM, Rooijmans HGM, et al: Outcome in conversion disorder: a follow up study. J Neurol Neurosurg Psychiatry 1995; 58: 750-752.

25. Gatfield PD, Guze SB: Prognosis and differential diagnosis of conversion reactions. Dis Nerv Syst 1962; 23: 623-631.

26. Slater ETO, Glithero E: A follow-up of patients as suffering from "hysteria."J Psychosom Res 1965; 9: 9-13.

27. Ford CV, Folks DG: Conversion disorder: an overview. Psychosomatics 1985; 26: 371-383.

28. Lazare A: Current concepts in psychiatry; conversion disorders. N Engl J Med 1981; 305: 745-748.

29. Jensen PS: Case report of conversion catatonia: indication for hypnosis. Am J Psychotherapy 1994; 88: 566-570.

30. Folks DG, Ford CV, Houck CA: Somatoform disorders, factitious disorders and malingering, in Clinical Psychiatry for the Medical Student. Philadelphia: J.B. Lippincott, 1994.

31. Hales RE, Yudofsky SC, Talbot JA: The American Psychiatric Press Textbook of Psychiatry, second edition. Washington, DC: American Psychiatric Press, 1994. 